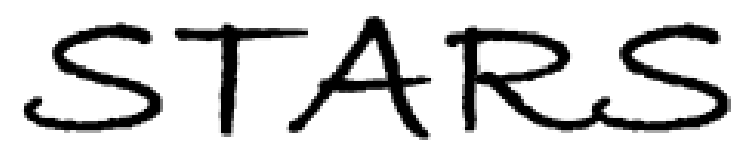

University of Central Florida

STARS

$1-1-2012$

\title{
Probing grain boundaries in ceramic scintillators using x-ray radioluminescence microscopy
}

Stephen R. Podowitz

Romain M. Gaumé

University of Central Florida

Robert S. Feigelson

Find similar works at: https://stars.library.ucf.edu/facultybib2010

University of Central Florida Libraries http://library.ucf.edu

This Article is brought to you for free and open access by the Faculty Bibliography at STARS. It has been accepted for inclusion in Faculty Bibliography 2010 s by an authorized administrator of STARS. For more information, please contact STARS@ucf.edu.

\section{Recommended Citation}

Podowitz, Stephen R.; Gaumé, Romain M.; and Feigelson, Robert S., "Probing grain boundaries in ceramic scintillators using x-ray radioluminescence microscopy" (2012). Faculty Bibliography 2010s. 3151. https://stars.library.ucf.edu/facultybib2010/3151

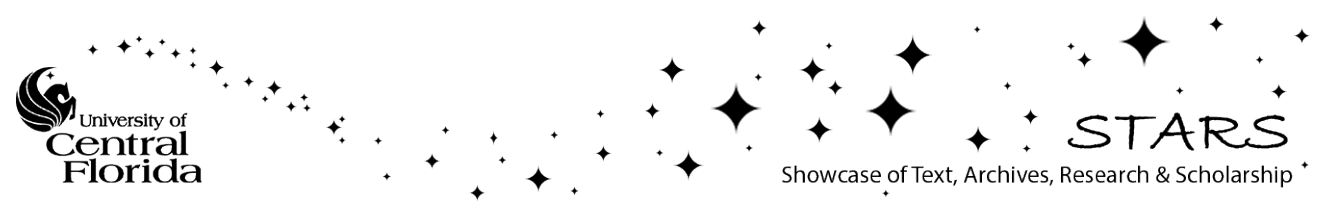




\section{Probing grain boundaries in ceramic scintillators using $x$-ray radioluminescence microscopy}

Cite as: J. Appl. Phys. 111, 013520 (2012); https://doi.org/10.1063/1.3676222

Submitted: 22 August 2011 . Accepted: 08 December 2011 . Published Online: 12 January 2012

Stephen R. Podowitz, Romain M. Gaumé, and Robert S. Feigelson

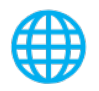

\section{ARTICLES YOU MAY BE INTERESTED IN}

Strontium and barium iodide high light yield scintillators

Applied Physics Letters 92, 083508 (2008); https://doi.org/10.1063/1.2885728

A neutron scintillator based on transparent nanocrystalline $\mathrm{CaF}_{2}$ : Eu glass ceramic

Applied Physics Letters 108, 153106 (2016); https://doi.org/10.1063/1.4945999

Mechanisms of nonstoichiometry in $\mathrm{Y}_{3} \mathrm{Al}_{5} \mathrm{O}_{12}$

Applied Physics Letters 93, 191902 (2008); https://doi.org/10.1063/1.3002303

\section{Applied Physics Reviews} Now accepting original research

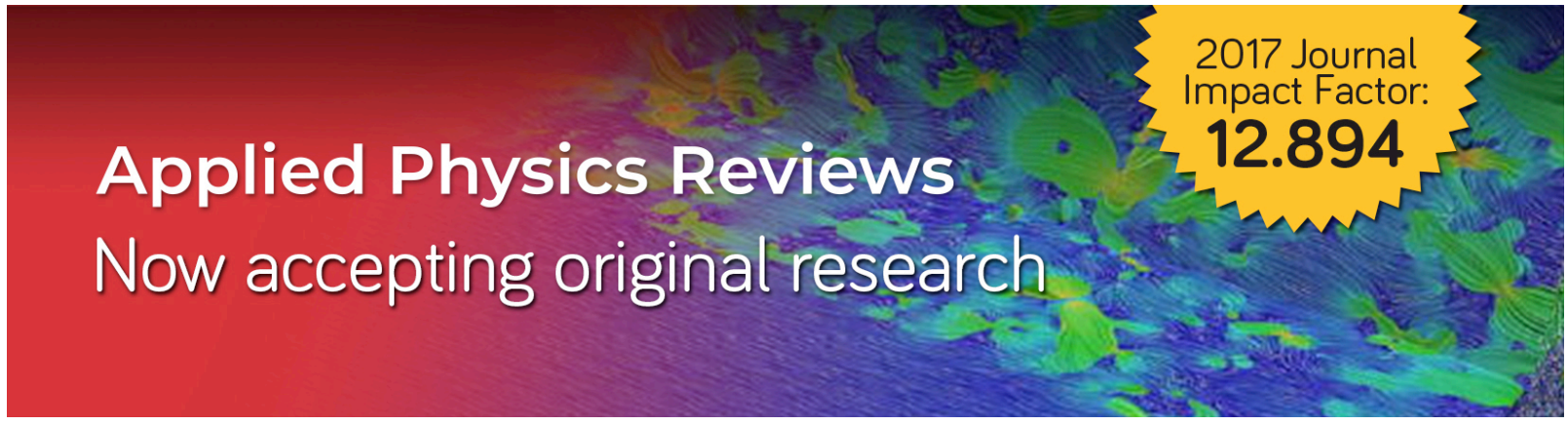




\title{
Probing grain boundaries in ceramic scintillators using $\mathrm{x}$-ray radioluminescence microscopy
}

\author{
Stephen R. Podowitz, ${ }^{1,2, a)}$ Romain M. Gaumé, ${ }^{1,3}$ and Robert S. Feigelson ${ }^{1,2}$ \\ ${ }^{1}$ Geballe Laboratory for Advanced Materials, Stanford University, Stanford, California 94305, USA \\ ${ }^{2}$ Department of Materials Science and Engineering, Stanford University, Stanford, California 94305, USA \\ ${ }^{3}$ College of Optics and Photonics, University of Central Florida, Orlando, Florida 32816, USA
}

(Received 22 August 2011; accepted 8 December 2011; published online 12 January 2012)

\begin{abstract}
$\mathrm{X}$-ray radioluminescence microscopy (XRLM), a novel fluorescence microscopy technique under

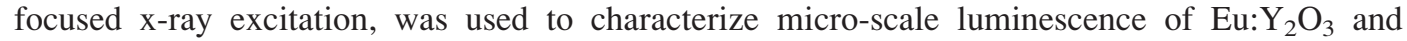
Ce:YAG transparent ceramics and bicrystals. The diffusion length of a known semiconductor measured by XRLM was found to be in agreement with previously measured values, illustrating its use for characterizing charge carrier transport. Emission intensity was found to drop at the boundaries in both Eu: $\mathrm{Y}_{2} \mathrm{O}_{3}$ and $\mathrm{Ce}: \mathrm{YAG}$ ceramics and bicrystals. The depletion in emission at grain boundaries was ultimately found to be related to charge carrier depletion (through either deep trapping or non-radiative recombination). A charge carrier diffusion model was used to understand the effect of grain boundaries on charge carrier transport in these scintillators. The diffusion model was found to accurately predict the spatial distribution of emission in a Ce:YAG single-crystal as a function of $\mathrm{x}$-ray excitation energy. Structural and chemical characterization of grain boundaries in an $\mathrm{Eu}: \mathrm{Y}_{2} \mathrm{O}_{3}$ ceramic using transmission electron microscopy and secondary ion mass spectrometry mapping showed an ordered boundary region and no detectable segregation of impurities or Eu, justifying the use of an abrupt boundary condition to determine boundary recombination velocities in these materials. The boundary recombination velocities were then used to show that, for ceramics with grain sizes $>\sim 20 \mu \mathrm{m}$, there would be a minimal effect from the detected charge carrier depletion at grain boundaries on their bulk x-ray radioluminescence intensity. Ultimately, this study illustrates how this new XRLM technique can be used to measure charge carrier diffusion properties and how it may be coupled with microstructural and micro-scale chemical analyses to fully investigate the effect of grain boundaries on scintillator properties. (C) 2012 American Institute of Physics. [doi:10.1063/1.3676222]
\end{abstract}

\section{INTRODUCTION}

Ceramic scintillators are a class of nuclear and radiological detector materials that have the potential to decrease production time and costs and provide for fabrication of near-net shape and larger-size materials compared to the single-crystal materials most often used for detector applications. Ceramic scintillators, such as $\operatorname{Pr}: \mathrm{Gd}_{2} \mathrm{O}_{2} \mathrm{~S}^{1}$ and $\mathrm{Eu}:(\mathrm{Y}, \mathrm{Gd})_{2} \mathrm{O}_{3},{ }^{2}$ have been used in X-ray computed tomographs (CT) for a number of years. More recently, progress on the fabrication of transparent ceramics of a number of scintillator materials, both cubic $^{3,4}$ and birefringent, ${ }^{5-7}$ has lead to the development of scintillator ceramics with superior properties for additional nuclear detection application areas. These include: (1) nuclear security and isotopic identification (energy resolutions down to $4.5 \%$ are achievable in transparent Gd-based garnets ceramics $\left.^{8}\right)$, (2) radiological detection $\left(\mathrm{Eu}: \mathrm{Lu}_{2} \mathrm{O}_{3}\right.$ transparent ceramics have been reported to have light yields of up to $75000 \mathrm{ph} / \mathrm{MeV}^{9}$ ), and (3) medical imaging (new Ce-doped garnets $^{10,11}$ and lutetium orthosilicates (Ce:LSO) ceramics ${ }^{12}$ have been shown to have fast decay times and high light yields).

\footnotetext{
a) Author to whom correspondence should be addressed. Electronic mail: podowitz@stanford.edu.
}

While it is known that point defects in single-crystal scintillators significantly affect performance by creating charge carrier traps or introducing non-radiative recombination pathways, the true effect of ceramic grain boundaries on scintillator performance has not been well characterized. Many studies of ceramic scintillators have pointed to "defects at the boundaries" as a possible source of degradation in scintillator performance and an origin of deep trapping. ${ }^{2,13,14,17}$ In one such study, Zych et al. ${ }^{15}$ reported a positive relationship between grain size and light output in two air-annealed, translucent ceramics of Ce:YAG that were processed under different conditions. They also observed a fast decay component under $\gamma$-ray excitation, which was $\sim 45 \mathrm{~ns}$ less than the decay of $\mathrm{Ce}^{3+}$ under direct excitation. This fast decay has not been reported elsewhere, ${ }^{13,16,18}$ although other studies have been exclusively based on unannealed ceramics.

A comparison of previous studies on trapping and other loss mechanisms in ceramic scintillators highlights the importance of separating out effects on scintillator performance from processing-related or impurity-related electronic defect states and states unique to the grain boundaries. This type of study has been absent in the scintillator literature, but in other materials for electronic, optoelectronic, and electrochemical applications, grain boundaries have been shown to have a 
strong effect on properties. ${ }^{19-23}$ A number of these studies have taken advantage of microscopy techniques, such as cathodoluminescence (CL) mapping and electron beam-induced current (EBIC) imaging, to spatially resolve luminescence or conductivity and compare these properties to the locations of grain boundaries or dislocations. ${ }^{24-26}$ These techniques are limited in their application, however, because they are both quite surface sensitive, due to the penetration depth of electrons in most useful optical materials, causing surface states to strongly affect the intensity maps. Moreover, EBIC may only be used to characterize electrical conductors.

A similar approach is used here to characterize insulating scintillator materials, where spatially resolved radioluminescence from excitation under a focused, monochromatic hard $\mathrm{x}$-ray source is measured, as opposed to cathodoluminescence from an electron beam. For hard x-rays, the attenuation length is on the order of tens of micrometers in typical scintillator materials. The emission distributions from spot excitations along lines intersecting grain boundaries were measured in order to compare the emission intensity near the boundary to that within the bulk of the grain. Two often-characterized scintillator materials, Eu: $\mathrm{Y}_{2} \mathrm{O}_{3}$ and $\mathrm{Ce}: \mathrm{Y}_{3} \mathrm{Al}_{5} \mathrm{O}_{12}$ (Ce:YAG), were used as model materials in this study. The chemical and structural properties of grain boundaries in the ceramic and bicrystal samples of these materials were characterized by $\mathrm{x}$ ray fluorescence (XRF) mapping, secondary ion mass spectrometry (SIMS) mapping, and transmission electron microscopy (TEM).

A charge carrier transport model was used to understand and quantify observed depletions in charge carrier concentrations at the grain boundaries as measured by $\mathrm{x}$-ray radioluminescence microscopy (XRLM). Charge carrier drift and diffusion models have been utilized to describe mechanisms for energetic losses of high-energy carriers during the conversion regime of scintillation, ${ }^{27,28}$ and the kinetics of scintillation have been described through charge carrier continuity equations. ${ }^{29,30}$ However, diffusion equations have not previously been used to describe the transport of charge carriers in inorganic scintillators, following their thermalization to the bottom of the conduction band or top of the valence band, prior to luminescent recombination. On the other hand, diffusion and continuity equations have accurately modeled CL and EBIC images of semiconductor materials. ${ }^{31-34}$ Ultimately, we develop a relationship between grain size and luminescence intensity in bulk ceramics of Ce:YAG and $\mathrm{Eu}: \mathrm{Y}_{2} \mathrm{O}_{3}$ using both XRLM characterization and the charge carrier transport model.

\section{EXPERIMENTAL PROCEDURES}

\section{A. X-ray radioluminescence microscopy setup}

XRLM studies were conducted using the $\mathrm{x}$-ray microprobe at beam line 2-3 of the Stanford synchrotron radiation lightsource (SSRL) within SLAC National Accelerator Laboratory. This beam line provided a focused, monochromatic $\mathrm{x}$-ray beam with spot size $<1.2 \mu \mathrm{m}$ at a flux of $\sim 10^{10}$ photons/sec. ${ }^{35}$ The $\mathrm{x}$-ray energy is tunable between 4.5 and $24 \mathrm{keV}$. The microprobe is both vertically and horizontally focused using Kirkpatrick-Baez x-ray optics. The beam line is primarily used as an x-ray absorption spectroscopy (XAS) imaging station and also has the capability to perform $\mathrm{X}$-ray fluorescence (XRF) mapping using a $\mathrm{Si}$ vortex detector. Samples were held vertically in the line of the beam and were positioned using sample stage translational motors in the $\mathrm{X}, \mathrm{Y}$, and $\mathrm{Z}$ directions. The sample motors had a positioning precision of $50 \mathrm{~nm}^{35}$

An objective microscope equipped with a Photometrics CoolSNAP $\mathrm{cf}^{2}$ monochrome charge coupled device (CCD) camera was incorporated into the standard beam line configuration, and visible light optics were used to collect and direct the emission from the sample produced under excitation from the x-ray microprobe. Emission distributions were imaged from the back surfaces of the samples in order to accommodate the optical microscopy setup within the existing configuration inside the hutch. A collecting lens was placed $15 \mathrm{~mm}$ behind the sample, and an aperture with a 3-mm diameter was affixed to the front of the lens. A focusing lens was placed $120 \mathrm{~mm}$ from the collecting lens and $105 \mathrm{~mm}$ from the objective of the microscope, so that the rear image plane of the two-lens system was at the working distance of the objective. Using this geometry, the real image of the emission distribution was in focus at the working distance of the microscope objective. Both the collecting and focusing lenses were achromatic doublets with 25$\mathrm{mm}$ diameters and 60-mm focal lengths. Achromatic doublet lenses were used to decrease spherical and chromatic aberrations. The two lenses had antireflective coatings that limited the reflection coefficient $(R)$ at both surfaces to $<1.5 \%$ in the $450-750 \mathrm{~nm}$ spectral range. An aluminumcoated mirror was placed in between the collecting and focusing lenses to redirect the light produced by the sample into the microscope objective, which was aligned along the axis parallel to the sample surface and offset by $88 \mathrm{~mm}$, as illustrated in Fig. 1.

The CCD imaging array of the camera was $1392 \times 1040$ pixels with each pixel cell $4.65 \times 4.65 \mu \mathrm{m}$, giving a detector resolution of $310 \mathrm{~nm}$ at a microscope magnification of $15 \times$. However, the lateral spatial resolution of the microscope was limited by the numerical aperture of the objective, such that its Abbe diffraction limit is between 325 and $527 \mathrm{~nm}$ for wavelengths between 400 and $650 \mathrm{~nm}$. Therefore, there was some minimal light bleeding between pixels. The aperture in front of the collection lens provided for a depth of field

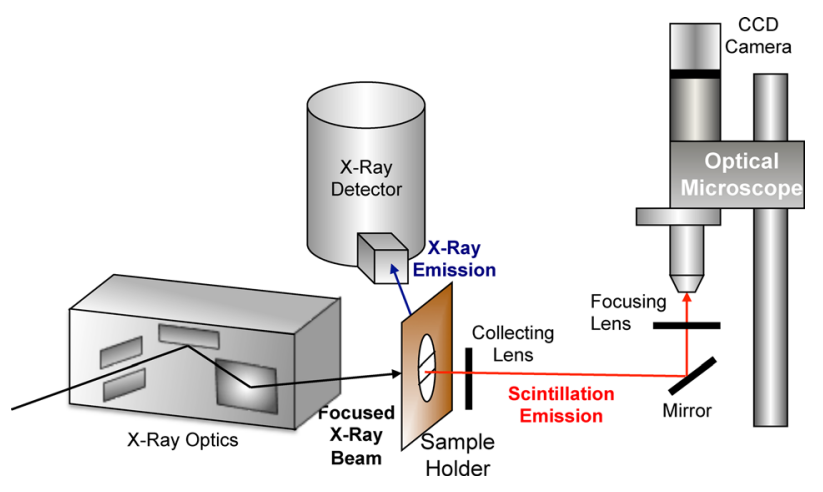

FIG. 1. (Color online) Schematic of XRLM setup. 
(DOF) that was between 14.8 and $24.1 \mu \mathrm{m}$ in this same range of wavelengths. This DOF is nearly the thickness of the samples, so that the microscope was in focus at all depths through each sample. A smaller DOF could be reached by removing the aperture in front of the collection lens.

In order to verify that the XRLM technique could be used to measure charge carrier transport behavior, the diffusion length $\left(L_{\text {diff }}\right)$ of a $\sim 5-\mu$ m-thick film of epitaxial GaAs on Ge with known properties was calculated from its emission distribution. The GaAs/Ge sample was thinned from the substrate surface down to $\sim 20 \mu \mathrm{m}$, and the GaAs surface was directed toward the collection lens so that its visible emission would not be absorbed within the Ge substrate layer before reaching the optical microscope. Emission spots were imaged at 15 locations within the sample, and the tails of the average emission distribution were fitted to a zerothorder Bessel function of the second kind $\left(\mathrm{K}_{0}\right)$ using a procedure described in Sec. IV B, with $L_{\text {diff }}$ as a fitting parameter, as shown in Fig. 2. The calculated diffusion length of $17.5 \pm 0.4 \mu \mathrm{m}$ is in good agreement with previously reported values $\left(\mathrm{L}_{\text {diff }}=17.1 \mu \mathrm{m}^{36}\right)$.

\section{B. Ceramic materials and sample preparation}

Four scintillator samples were characterized by XRLM: a 0.1 at. $\%$ Ce:YAG ceramic, a 0.1 at. \% Ce:YAG bicrystal made by diffusion bonding two single crystals, and two 5 at. $\%$ Eu: $\mathrm{Y}_{2} \mathrm{O}_{3}$ ceramics. All samples were ground and polished to below a single grain thickness $(\sim 20 \mu \mathrm{m})$ and mounted on a copper foil over a 3-mm hole in preparation for XRLM measurements. Samples were thinned to avoid interactions with multiple boundaries and to limit the effect of scattering from any residual porosity.

The transparent Ce:YAG ceramic was prepared and sintered through the same procedure as the one described in Ref. 37 with $>99.999 \%$ purity $\mathrm{Y}_{2} \mathrm{O}_{3}, \alpha-\mathrm{Al}_{2} \mathrm{O}_{3}$, and $\mathrm{CeO}_{2}$ from Inframat Advanced Materials used as starting powders. Figure 3(a) shows the in-line transmission and X-ray radioluminescence (XRL) emission spectra of the Ce:YAG sample characterized in this study. The characteristic $4 f-5 d \mathrm{Ce}^{3+}$ absorption $(342,460 \mathrm{~nm})$ and emission $(528,560 \mathrm{~nm})$ bands

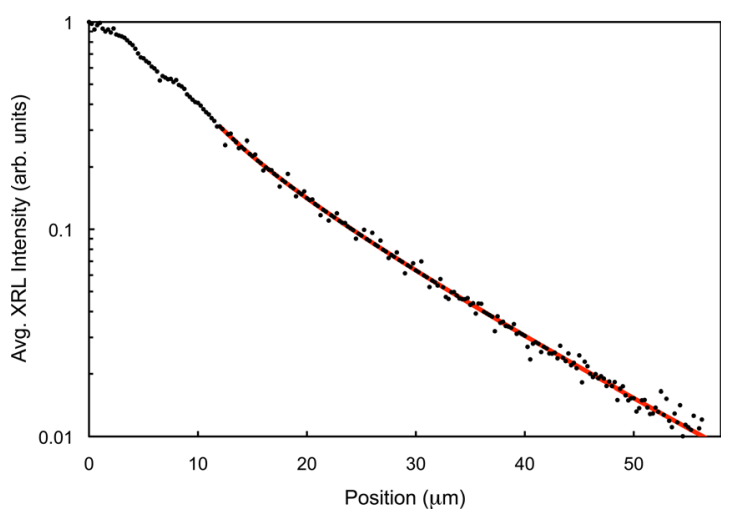

FIG. 2. (Color online) Average X-ray radioluminescence (XRL) intensity (dots) of epitaxial GaAs on Ge as a function of distance from the center of the $8.1 \mathrm{keV} x$-ray excitation beam. The line shows the fit of emission distribution tail using a $\mathrm{K}_{0}$ function in order to calculate $\mathrm{L}_{\text {diff. }}$. were observed. ${ }^{38}$ The low-intensity, ultraviolet emission band is likely caused by charge transfer between $\mathrm{Ce}^{3+}$ and antisite defects. ${ }^{39,40} \mathrm{~A}$ broad and shallow defect absorption band was also observed from $\sim 650-750 \mathrm{~nm}$. The in-line optical transmission in the spectral region of the emission band was found to be $61-62 \%$ for a 2.75 -mm-thick sample, as compared to the Fresnel limit for YAG of $84 \%$. $^{41}$

The Ce:YAG bicrystal was produced through diffusion bonding two parts of a cut single crystal back together. The single crystal, obtained from Hilger Crystals, was grown by the Czochralski process. The single crystal was cut normal to the (111) plane and then the cut surface of each half was polished to prepare the sample for optical bonding. The halves were optically bonded together and then uniaxially pressed at $1100^{\circ} \mathrm{C}$ and $10 \mathrm{MPa}$ in an inert atmosphere. Samples for XRLM characterization were cut from the center of the bonded bicrystal. Eu: $\mathrm{Y}_{2} \mathrm{O}_{3}$ transparent ceramics were prepared using the same starting material (mixture of $\mathrm{Y}_{2} \mathrm{O}_{3}$ and $\mathrm{Eu}_{2} \mathrm{O}_{3}$ powders) and a similar procedure to the one described in Ref. 42. Both ceramics were hot-pressed at a maximum temperature of $1600^{\circ} \mathrm{C}$ and maximum pressure of $40 \mathrm{MPa}$. However, ceramic "YO1" was sintered through a single ramp up to maximum pressure after outgassing at $1150^{\circ} \mathrm{C}$, while temperature and pressure were ramped up step-wise during sintering of ceramic "YO2." The total sintering times for $\mathrm{Eu}: \mathrm{Y}_{2} \mathrm{O}_{3}$ ceramics $\mathrm{YO} 1$ and $\mathrm{YO} 2$ were 16 and $25 \mathrm{~h}$,
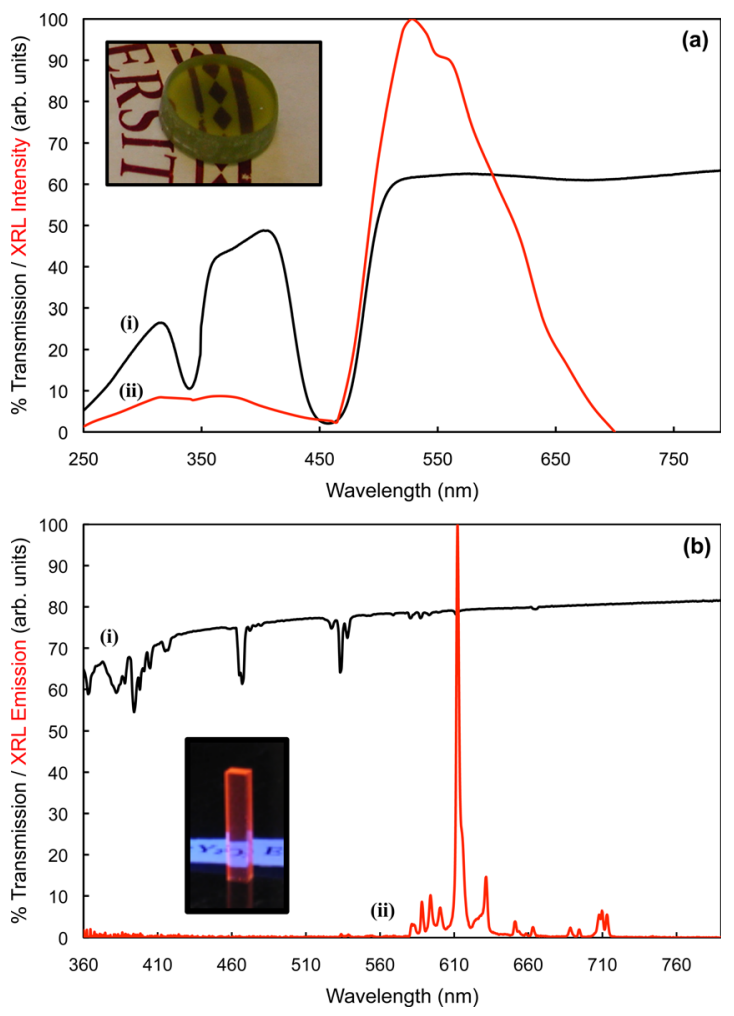

FIG. 3. (Color online) Optical transmission (curves i) and XRL emission (curves ii) spectra of (a) a 2.75-mm-thick sample of the Ce:YAG ceramic used in this study and (b) a 2-mm-thick sample of Eu: $\mathrm{Y}_{2} \mathrm{O}_{3}$ ceramic YO2. XRL spectra were taken under $40 \mathrm{keV}$ and $50 \mathrm{keV}$ peak excitations, respectively. The insets are photographs of bulk ceramics of (a) Ce:YAG in ambient light and (b) the YO2 sample under ultraviolet light with red emission from $\mathrm{Eu}^{3+}$, respectively. 

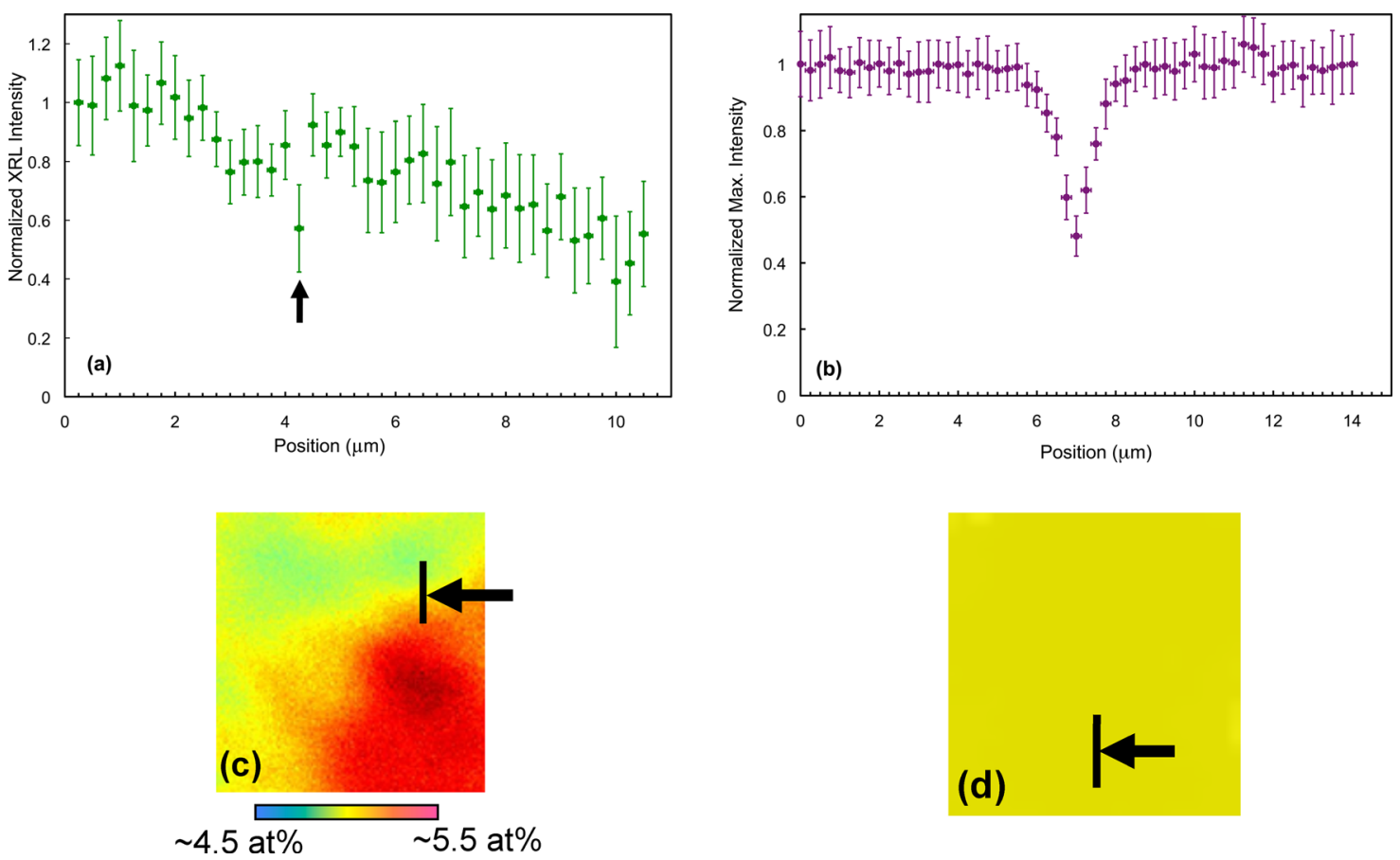

FIG. 4. (Color online) Maximum XRL intensity of emission spots excited at positions $0.25 \mu \mathrm{m}$ apart from each other along lines that cross a boundary in samples (a) YO1 and (b) YO2. Intensities were normalized to the initial point on the line. XRF maps of Eu (c) in YO1 showing line across which (a) was taken and (d) in YO2. The arrows in (c) and (d) identify the boundaries at the positions of $4.25 \mu \mathrm{m}$ in (a) and $7 \mu \mathrm{m}$ in (b), respectively.

respectively, which provided less time for inter-diffusion of atomic species in YO1, causing small Eu concentration gradients that were not observed in YO2, as discussed in Sec. III A. Both ceramics were air annealed at $1100^{\circ} \mathrm{C}$ for $72 \mathrm{~h}$ to reintroduce oxygen lost during sintering in a reducing environment. After annealing, small segments of the samples were polished and chemically etched to measure their grain sizes using scanning electron microscopy (SEM) and the intercept method. The optical properties of samples were also characterized after annealing. Only $\mathrm{Eu}^{3+}$ absorption peaks were observed in the in-line optical transmission spectra (Fig. 3(b)) of both samples. ${ }^{43}$ The percent transmissions of 2-mmthick samples of $\mathrm{YO} 1$ and $\mathrm{YO} 2$ at $600 \mathrm{~nm}$ were $52.8 \%$ and $78.7 \%$, respectively, compared to $81.6 \%$ at the Fresnel limit of $\mathrm{Y}_{2} \mathrm{O}_{3} .{ }^{44}$ The XRL spectra (Fig. 3(b)) of both samples contained the $\mathrm{Eu}^{3+}$ emission peaks from the ${ }^{5} \mathrm{D}-{ }^{7} \mathrm{~F}$ transitions. ${ }^{45}$

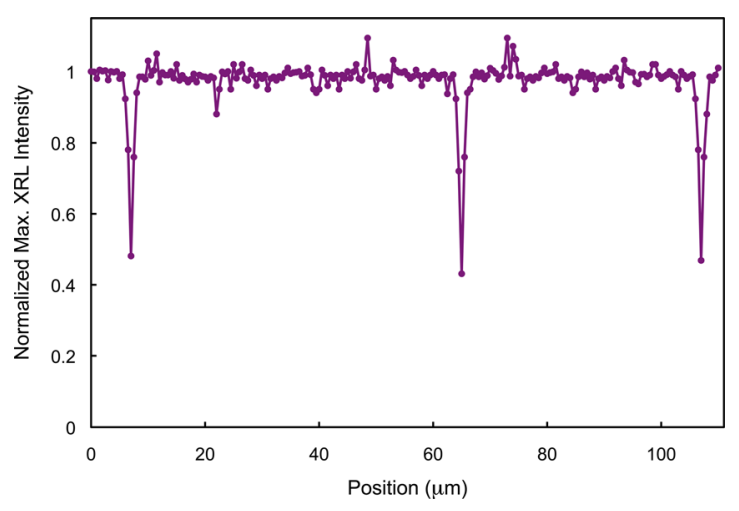

FIG. 5. (Color online) Maximum XRL intensities of emission spots measured at positions spaced $0.5 \mu \mathrm{m}$ apart along a line that crosses multiple boundaries in sample YO2. Intensities are normalized to the initial point on the line.

\section{Locating grain boundaries for XRLM characterization}

Localized scintillation emission intensities were measured in the ceramics and bicrystal by moving the sample by increments of $0.25 \mu \mathrm{m}$ so that the x-ray beam was focused one spot at a time at points along several $\sim 14-\mu \mathrm{m}$-long lines intersecting boundaries. At each spot, a number of images of the emission's spatial distribution were acquired and were used to calculate an averaged distribution. The maximum intensities (i.e., the peak) of the averaged distributions at each location along a line were compared in order to visualize the effect of the boundary. The excitation energy was held at $8.1 \mathrm{keV}$ for all measurements, unless otherwise specified.

Boundaries were located through different means for each sample. For the Eu: $\mathrm{Y}_{2} \mathrm{O}_{3}$ ceramic with Eu concentration gradients (YO1), boundaries were identified by using this concentration variation. Eu concentrations were mapped using $\mathrm{x}$-ray fluorescence from the $\mathrm{K} \beta$ peak of Eu using the $\mathrm{Si}$ vortex detector within the beam line hutch. For the other $\mathrm{Eu}: \mathrm{Y}_{2} \mathrm{O}_{3}$ ceramic (YO2), Eu maps showed little contrast, none of which was clearly associated with boundaries (see Fig. 4(d)). Therefore, boundaries were located by performing spot excitations along much longer lines on the order of the average grain size ( $>54.1 \mu \mathrm{m})$ to observe regions of symmetric depletion. Figure 5 shows the XRL intensities at spots along a $110-\mu \mathrm{m}$ line in this ceramic, where the separation between the two depletion regions is close to the average grain size. Grain boundaries in the Ce:YAG ceramic were located using a similar method. The exact location of the bonding interface in the Ce:YAG bicrystal was identified using the CCD camera with the sample backlit. 
Once a boundary was located, spots along a line straddling the boundary were measured over 2 to 3 passes to confirm reproducibility and the absence of hysteresis.

\section{TEM, SIMS, and confocal microscopy}

An FEI Tecnai $G^{2}$ F20 X-TWIN transmission electron microscope (TEM) was used to characterize the crystallinity of grain boundaries in sample YO2. The point-to-point resolution of the microscope was $2.5 \AA$. Thinned samples were ion milled, and the boundaries around the hole that formed during milling were imaged.

A CAMECA NanoSIMS 50L (secondary ion mass spectrometer with nanoscale spatial resolution) with an oxygen ion gun was used to map the content of Eu dopant and other possible impurities in sample YO2. The trace impurities mapped in this study $(\mathrm{Ca}, \mathrm{Si}, \mathrm{Fe}, \mathrm{La}$, and $\mathrm{Zr})$ were those with the highest concentrations measured by the supplier of the starting powders, using inductively coupled plasma mass spectrometry (ICP-MS). Ion currents were mapped over regions within the ceramics and measured along $\sim 24-\mu \mathrm{m}$ lines crossing a boundary at $47-\mathrm{nm}$ increments while sputtering over an area of $0.25 \mu \mathrm{m}^{2}$ for 10 seconds at each spot.

A WITec alpha300 S confocal microscope with an argon laser was used to map the emission from direct excitation of $\mathrm{Eu}^{3+}$ in the YO2 sample. The argon laser excited the ${ }^{5} \mathrm{D}_{1}$ and ${ }^{5} \mathrm{D}_{2}$ absorptions of $\mathrm{Eu}^{3+}$ in $\mathrm{Y}_{2} \mathrm{O}_{3}$. Emission spectra from focused laser excitation and confocal laser scanning micrographs of the 611-nm Eu ${ }^{3+}$ peak were obtained.

\section{EXPERIMENTAL RESULTS AND DISCUSSION}

\section{A. Micro-scale scintillation across boundaries}

\section{1. $\mathrm{Eu}: \mathrm{Y}_{2} \mathrm{O}_{3}$}

The maximum XRL intensities plotted in Figs. 4, 5, and 6 were calculated from spatial distributions of the emission profiles and were normalized to the value at the beginning of each line (nominal position $=0 \mu \mathrm{m}$ ). The error bars on each of the intensities signify the $95 \%$ confidence interval of its mean value.

Figure 4(a) shows the normalized maximum XRL intensity along the $10.5-\mu \mathrm{m}$ line identified in Fig. 4(c). The location of a grain boundary is indicated by the arrow and coincides with a position of $4.25 \mu \mathrm{m}$ in Fig. 4(a). Other than at this position, the trend in intensity followed the change in Eu concentration. Because the Eu concentration varied from $\sim 4.5 \mathrm{~mol} . \%$ to $\sim 5.5 \mathrm{~mol} . \%$ in this area of the sample and the light yield of $\mathrm{Eu}^{3+}: \mathrm{Y}_{2} \mathrm{O}_{3}$ has been shown to vary roughly linearly with concentration over this range, ${ }^{46}$ the overall trend in XRL intensity with position likely originated from this difference in $\mathrm{Eu}^{3+}$ concentration along the line.

In contrast, the depletion regions in YO2 (e.g., Figure 4(b)) were much more distinctive than those observed in YO1. Significant depletion was found over a region $\sim 1 \mu \mathrm{m}$ wide, and clear depletion began to occur over a region $\sim 2 \mu \mathrm{m}$ wide. The effect of Eu concentration gradients within YO1 on local emission intensity largely obscured any effect of the boundary, such as that observed in $\mathrm{YO}$ 2, beyond a narrow width right at the boundary.

\section{Ce:YAG}

Maximum XRL intensities in the Ce:YAG bicrystal (Fig. 6(a)) and the ceramic sample (Fig. 6(b)) had a similar shape to that of sample YO2. While the attenuation regions at the boundaries characterized in the Ce:YAG samples had very similar widths $(\sim 2-2.5 \mu \mathrm{m})$ and depths $(30-35 \%)$ compared to each other, they were wider and deeper than those characterized in YO2. The similarity between the Ce:YAG samples suggests that the bicrystal boundary may be a good model for a ceramic grain boundary in this context and that there was no significant additional effect from surface damage during polishing of the crystals before bonding.

A difference in the emission intensity at grain boundaries, such as the ones observed here, has been variously attributed to: (1) a decrease in material thickness due to grain boundary grooving at the surfaces ${ }^{47}$ (2) light channeling due to a difference in refractive index across a boundary, ${ }^{48}(3)$ excited state quenching of activator ions from defect states at the boundary, ${ }^{49,50}$ and/or (4) depletion of charge carriers at boundary states prior to recombination at luminescent centers. ${ }^{51-56}$

For effect 1, the volume of absent material within the grain boundary groove must be of comparable size to the emission volume. Because the attenuation lengths of Eu: $\mathrm{Y}_{2} \mathrm{O}_{3}$ and $\mathrm{Ce}: \mathrm{YAG}$ at $8.1 \mathrm{keV}\left(16.5 \mu \mathrm{m}\right.$ and $31.7 \mu \mathrm{m},{ }^{57}$ respectively) are close to the thickness of the samples, a significant effect on XRL intensity from grooves at the surface
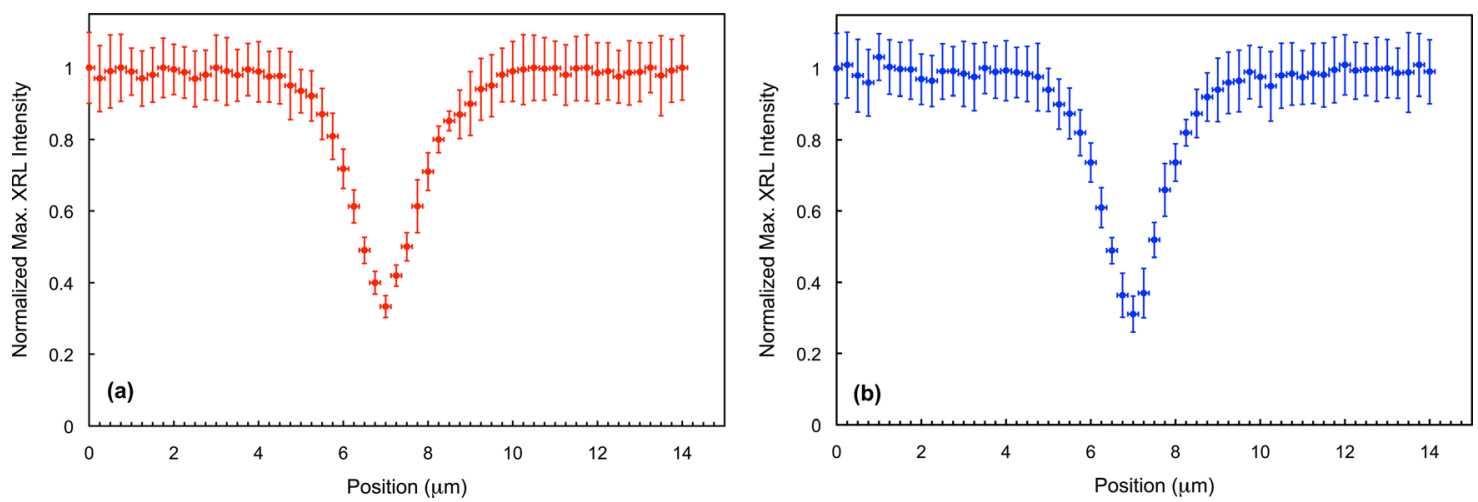

FIG. 6. (Color online) Maximum XRL intensity of emission spots excited at positions $0.25 \mu \mathrm{m}$ apart from each other along lines that cross a boundary in a Ce:YAG (a) bicrystal and (b) ceramic. Intensities were normalized to the initial point on the line. 


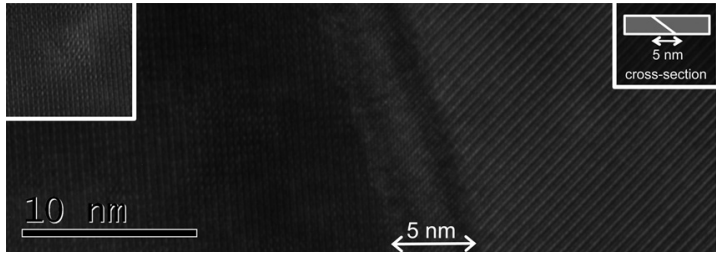

FIG. 7. TEM image of grain boundary in Eu: $\mathrm{Y}_{2} \mathrm{O}_{3}$ ceramic, showing lattice fringes of both grains that extend through the $\sim 5 \mathrm{~nm}$ overlap near the boundary between the two grains. A TEM image of typical dislocation loop is shown in the inset on the top left. A schematic of the thinned TEM sample with a boundary at an angle to the surface is shown in the inset on the top right.

is unlikely. As an example, even for an aggressively thermally etched $\mathrm{Al}_{2} \mathrm{O}_{3}$ ceramic, grooves were only $\sim 450 \mathrm{~nm}$ wide and $50 \mathrm{~nm}$ deep. ${ }^{58}$ If similarly large grooves were present in our samples, the missing area would account for only $0.05-0.1 \%$ of the observed depletion in intensity at the boundary.

Light channeling (effect 2) is also unlikely in these materials because of their cubic crystal structures and isotropic refractive indices. Additionally, light channeling would typically lead to an increase in intensity at the grain boundaries. ${ }^{48}$

The remaining effects ( 3 and 4 ) alter scintillation behavior due to defect states in the electronic band structure created by either chemical or structural defects. Such chemical defects may consist of impurity and dopant segregation near the boundary, ${ }^{59}$ and structural defects may arise from dislocation generation and long-range disorder within the "mantle" of the grain. ${ }^{60,61}$ Furthermore, even at grain boundaries with nearly coherent bonding, shallow energy levels have been shown to exist below the conduction band. ${ }^{51-55}$ Additional deeper electronic states may exist within the dislocation cores near some boundaries, caused by the location of the vacuum level within the bandgap. ${ }^{56}$ Such defect states that are isolated at boundaries may also cause trapping over a much more extended region, due to the kinetics of charge carrier diffusion.

The remainder of this paper focuses on identifying the origins of XRL depletion at the boundary and extending its effect to bulk scintillation properties. In an effort to identify which effects were operative here, SIMS and TEM were used to characterize the chemical and structural properties of the boundaries in the YO2 sample. Confocal laser scanning microscopy was used to investigate the emission from the direct excitation of $\mathrm{Eu}^{3+}$ at energies below the bandgap, in contrast to the cross-bandgap excitation used for XRLM.

\section{B. Structural and chemical characterization of boundaries}

Based on transmission electron microscopy (TEM) and secondary ion mass spectrometry (SIMS) studies, neither significant structural (dislocation segregation and long-range structural disorder) nor chemical (dopant and impurity segregation) effects at the boundaries were observed in the $\mathrm{YO} 2$ sample.

Figure 7 shows a TEM image of a typical grain boundary in the region of the sample used for XRLM characterization. The $\sim 5 \mathrm{~nm}$ width of the boundary in the image appears to be a region of overlap between the two grains on either side of the boundary (Fig. 7, right inset), because the lattice fringes of each of the grains extend through the region. Within a distance of $\sim 10 \mathrm{~nm}$ from the boundary, the lattice is slightly distorted. A very low concentration of line defects were present within the sample $(<\sim 10 /$ grain) (Fig. 7, left inset). Typically, these line defects were close to the edge of the distorted region, but also present within the bulk of the grain. The observed locations of line defects indicate that they may accommodate lattice mismatch across the boundary, due to a difference in grain orientation. However, while some disorder in the crystalline structure was observed near the boundaries, there still was a strong crystalline order at the boundary, and any increased concentration of structural defects was present within a very limited width around it. Although additional electronic states from these structural defects may serve as trapping and non-radiative recombination centers, ${ }^{25}$ their localized concentration only extended over 1/100th of the width of the scintillation intensity depletion region measured by XRLM.

Therefore, any effect that the disorder near the boundary may have on scintillation should be considered together with the effect of electronic defects at the boundary.

Chemical segregation at boundaries within ceramics can also cause differences in scintillation emission. The ${ }^{89} \mathrm{Y}$ and ${ }^{153} \mathrm{Eu}$ SIMS maps of the region characterized by XRLM are shown in Fig. 8. The ratio of the Eu to Y ion currents in each grain of the maps was found to be the same, which confirms the conclusions drawn from the absence of contrast in XRF maps measured simultaneously to XRLM measurements. The contrast variation between grains seen in Fig. 8 arose from the effect of crystallographic orientation on the ion current intensity, not concentration variation. ${ }^{62}$

The SIMS measurements showed no preferential segregation of $\mathrm{Eu}$ or other impurities at grain boundaries with a spatial resolution $(47 \mathrm{~nm})$ much less than the observed
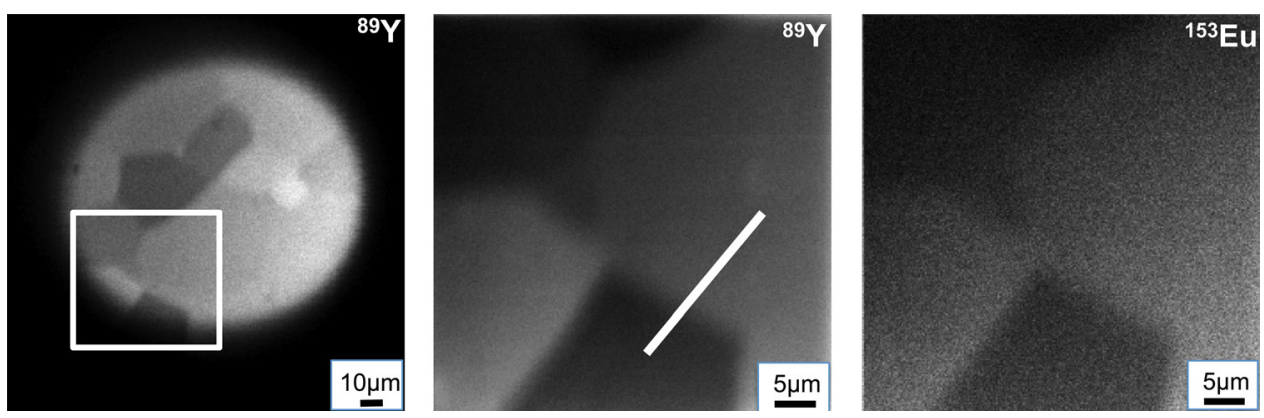

FIG. 8. (Color online) SIMS maps of (a) ${ }^{89} \mathrm{Y}$ (showing the circular aperture on the ion beam), (b) ${ }^{89} \mathrm{Y}$ in the boxed region in (a), and (c) ${ }^{153} \mathrm{Eu}$ of the same region as in (b). The line in (b) shows the length of the line scan presented in Fig. 9. 


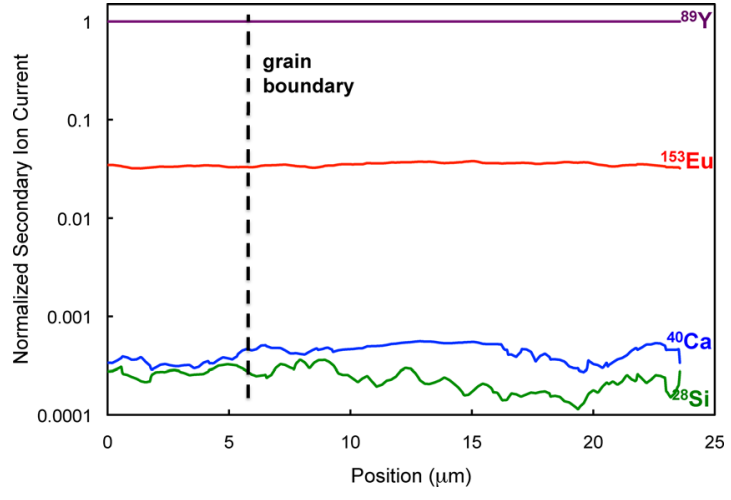

FIG. 9. (Color online) Secondary ion mass spectrometry (SIMS) line profile across a grain boundary for ${ }^{89} \mathrm{Y},{ }^{153} \mathrm{Eu},{ }^{40} \mathrm{Ca}$, and ${ }^{28} \mathrm{Si}$ along the line in Fig. 8 (b). Ion currents are normalized to that of ${ }^{89} \mathrm{Y}$ at each position. The position of the grain boundary is indicated by the dashed line.

emission depletion width (1-2 $\mu \mathrm{m})$. Figure 9 shows a typical line profile for $\mathrm{Eu}$ and two of the major impurities across the grain boundary in Fig. 8(b). The ${ }^{56} \mathrm{Fe}$ and ${ }^{92} \mathrm{Zr}$ were at $<2$ counts per 15 msec. No ${ }^{139}$ La ion current was detected.

\section{Fluorescence confocal microscopy of emission from activator ion}

Figure 10 shows a confocal microscopy image of the $611 \mathrm{~nm}$ emission of the YO2 sample under excitation from an argon laser. At this wavelength, the ${ }^{5} \mathrm{D}$ multiplet of $\mathrm{Eu}^{3+}$ is excited. The emission intensity was found to vary only right at the boundaries. Also, the emission spectrum did not shift across the boundary.

Therefore, the decrease in emission intensity observed at the grain boundaries by direct excitation of $\mathrm{Eu}^{3+}$ was not as wide as that measured by XRLM, making excited state quenching of activator ions an unlikely source of the depletion. It is worth noting that concentration quenching was not even observed in $\mathrm{Eu}: \mathrm{Y}_{2} \mathrm{O}_{3}$ ceramic $\mathrm{YO}$, where the local Eu con-

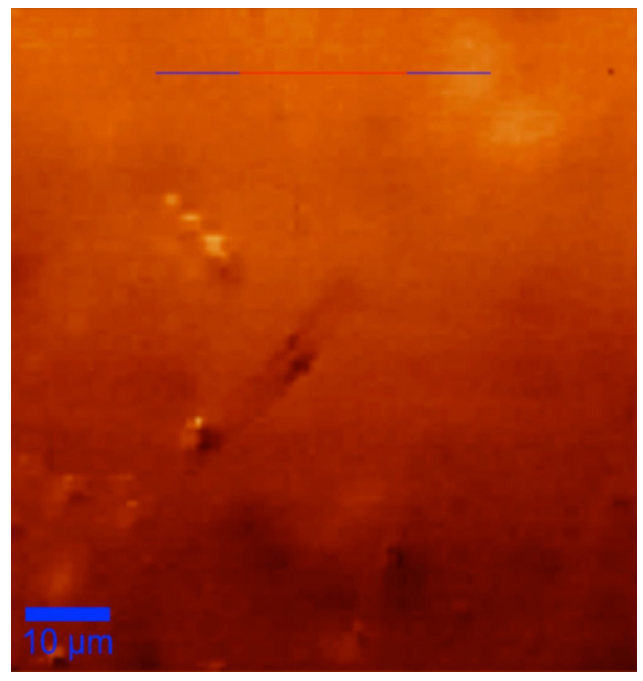

FIG. 10. (Color online) Scanning fluorescence confocal microscopy image of 611-nm emission from $\mathrm{Eu}^{3+}$ at a depth of $5 \mu \mathrm{m}$ in $\mathrm{Eu}: \mathrm{Y}_{2} \mathrm{O}_{3}$ ceramic YO2 under 488-nm excitation. centrations never reached above $\sim 5.5$ at. $\%$, which is below the Eu concentration at which quenching has been reported. ${ }^{46}$

\section{MODELING RESULTS AND DISCUSSION}

The experimental results presented above showed that charge carrier depletion at electronic defect states located in the immediate vicinity of the boundary led to the decrease in XRL intensity. To verify this effect, we began our analysis with a charge carrier transport model, which will be introduced in Sec. IV A. Then, using this model and experimentally measured transport parameters, "boundary recombination velocities" were calculated by fitting simulated XRL profiles to measured data as a method of quantifying the effect of the grain boundaries on XRL intensity.

\section{A. Charge carrier transport model}

The spatial extent of an emission distribution represents the volume over which charge carriers are generated and subsequently transported before radiatively recombining at activator ions or other radiative sites within the host material. Thus, the distributions measured in this study provide information on the nature of both charge carrier generation and transport in $\mathrm{Eu}: \mathrm{Y}_{2} \mathrm{O}_{3}$ and $\mathrm{Ce}: \mathrm{YAG}$. Generally, the spatial distribution of free carriers within a material under steadystate, ionizing excitation can be described by the continuity equation,

$$
D \nabla^{2} n-\frac{n}{\tau}+S(\mathbf{r})=0
$$

where $D$ is the diffusion coefficient of the charge carrier of interest (i.e., electron, hole, ambipolar, exciton), $n$ is the charge carrier concentration, $\tau$ is the lifetime of the carrier, and $S(\mathbf{r})$ is a spatially dependent carrier source term. Similar charge carrier diffusion models have been used extensively to describe conductivity in semiconductors since the results of the Haynes-Shockley experiment were reported. ${ }^{63}$

In its time-dependent form, Eq. (1) has also been used to describe the kinetics of emission from photoelectric semiconductor materials, ${ }^{64-67}$ where the emission intensity is assumed to be proportional to the minority charge carrier concentration. A similar approach can be used to describe the transport of charge carriers in inorganic, insulating materials excited by ionizing radiation, ${ }^{68-70}$ such as the scintillators investigated here.

As mentioned in the introduction, charge carrier transport in inorganic scintillators most often occurs through trapping at activator ions, sometimes in the presence of deeper trapping (and, thus, de-trapping) states. Also, transport may occur through hopping between transport states, such as is the case for small polarons. Nonetheless, the infinitesimal generator for the stochastic process that describes free carrier motion also applies to transport under these conditions. ${ }^{71}$ In the case of charge carrier diffusion in ionized insulators, $D$ can be treated as the an effective ambipolar diffusion coefficient, and $\tau$ then represents the contribution from the rates of trapping and de-trapping at the recombination (both radiative and non-radiative) and 
trapping sites. Such a value of $\tau$ is expressed in the scintillation decay time, as will be discussed in more detail in Sec. IV B.

With a radially symmetric, Gaussian source term and no boundary conditions imposed, the solution to Eq. (1) can be written as ${ }^{72}$

$$
I(r)=\frac{S_{0}}{2 \pi \sigma} \int_{0}^{\infty} e^{-\left(r^{2}+\xi^{2}\right) / 2 \sigma^{2}} I_{0}\left(2 r \xi / 2 \sigma^{2}\right) K_{0}\left(\xi / L_{\text {diff }}\right) \xi d \xi,
$$

where $I$ is the emission intensity, $r$ is the radial distance from the center of the source distribution, $S_{0}$ is the maximum value of the Gaussian source term, $L_{\text {diff }}$ is the effective diffusion length, $\sigma$ is the standard deviation of the source term (where $2 \sigma \sqrt{2 \ln 2}$ is the full-width at half maximum (FWHM)), $\xi$ is a spatial integration vector, and the $\mathrm{I}_{0}$ and $\mathrm{K}_{0}$ are the zeroth-order modified Bessel functions of the first and second kind. When $r \gg \sigma$ (i.e., a couple of microns from the source), Eq. (2) approximates as

$$
I(r) \propto K_{0}\left(r / L_{d i f f}\right) .
$$

Therefore, $L_{\mathrm{diff}}$ may be calculated by fitting the tail of an emission distribution with a $\mathrm{K}_{0}$ function. The effective diffusion coefficient in Eq. (1) may then be experimentally determined from calculated values of $L_{\mathrm{diff}}$ and the measured scintillation decay times $(\tau)$, using

$$
D=\frac{L_{\text {diff }}^{2}}{\tau} \text {. }
$$

To understand the physical parameters associated with the observed emission intensity depletion in the boundary region, a boundary condition that could account for the effect of sink states (deep traps and non-radiative recombination centers) was used to simulate emission distributions in our Eu: $\mathrm{Y}_{2} \mathrm{O}_{3}$ and Ce:YAG samples. Because limited segregation of dopants, impurities, and structural defects was observed at the boundaries in these materials, an abrupt boundary condition was found to be an appropriate assumption. The boundary condition ${ }^{73}$

$$
\vec{n} \cdot \nabla I=\frac{I}{D / s}
$$

was used to account for rate-limited, non-radiative recombination at a boundary surface, where $s$ is the boundary recombination velocity and $\vec{n}$ is the unit vector normal to the boundary. As to be discussed in Sec. IV D, calculated values for $s$, based on solutions to Eqs. (1) and (5), were used to quantify the effect of a nearly abrupt boundary on the depletion of nearby charge carriers.

\section{B. Effective charge carrier diffusion lengths and decay times}

The effective charge carrier diffusion lengths (Table I) in Eu: $\mathrm{Y}_{2} \mathrm{O}_{3}$ and $\mathrm{Ce}: \mathrm{YAG}$ ceramics were calculated from XRL emission distributions (e.g., Figure 11). Each emission profile consisted of three regions: (1) one that decreased faster than exponential, (2) a second that decreased nearly exponentially
TABLE I. Measured effective diffusion lengths of samples.

\begin{tabular}{lccc}
\hline \hline Sample & $\begin{array}{c}\text { Energy } \\
(\mathrm{keV})\end{array}$ & $\begin{array}{c}\text { Effective diffusion } \\
\text { length }(\mu \mathrm{m})\end{array}$ & $\begin{array}{c}\text { Boundary recombination } \\
\text { velocity }(\mathrm{cm} / \mathrm{s})\end{array}$ \\
\hline Ce:YAG bicrystal & 5.0 & $0.99 \pm 0.03$ & $\ldots$ \\
& 8.1 & $0.98 \pm 0.03$ & 8500 \\
& 10.0 & $1.01 \pm 0.03$ & $\ldots$ \\
Ce: $\mathrm{YAG}_{2}$ ceramic & 17.04 & $0.96 \pm 0.04$ & $\ldots$ \\
Eu: $\mathrm{Y}_{2} \mathrm{O}_{3}$ ceramic \#1 & 8.1 & $0.89 \pm 0.07$ & 8900 \\
Eu: $\mathrm{Y}_{2} \mathrm{O}_{3}$ ceramic \#2 & 8.1 & $1.47 \pm 0.14$ & $\ldots$ \\
\hline \hline
\end{tabular}

(the linear section on the log-linear plot), and (3) a third at the detection limit below the level of background. Because the Gaussian tails of the x-ray source distribution falloff faster than exponential, the exponential-like "tails" that arise from transport of charge carriers generated within the extremes of the Gaussian source volume were easily identified. These tails were fit with a $\mathrm{K}_{0}$ function (an exponentiallike function) using a least-squares fitting method to determine $L_{\text {diff }}$ according to the relationship in Eq. (3).

In order to confirm that Eq. (3) can be used to isolate the generation and conversion volume from its extended transport volume, thus making it possible to calculate charge carrier transport parameters from XRLM results, values of $L_{\text {diff }}$ calculated from emission under four different excitation energies were compared. This comparison was done for the Ce:YAG bicrystal because emission spots could be imaged at positions far from the boundary, so that diffusion parameters within an individual crystallite could be calculated without any substantial effect from depletion at the boundary. Effective charge carrier diffusion lengths were calculated from each of the four distributions in Fig. 12(a) through a similar procedure to the one used for the ceramics. The calculated $L_{\text {diff }}$ 's were found to be nearly identical for the four excitation energies (Table I).

Effective charge carrier lifetimes $(\tau)$ were calculated from bulk scintillation emission decay after $\gamma$-excitation (Table II). In the cases where multiple decay components were observed, an effective $\tau$ was calculated based on the relative contributions of the components. The decay in scintillation

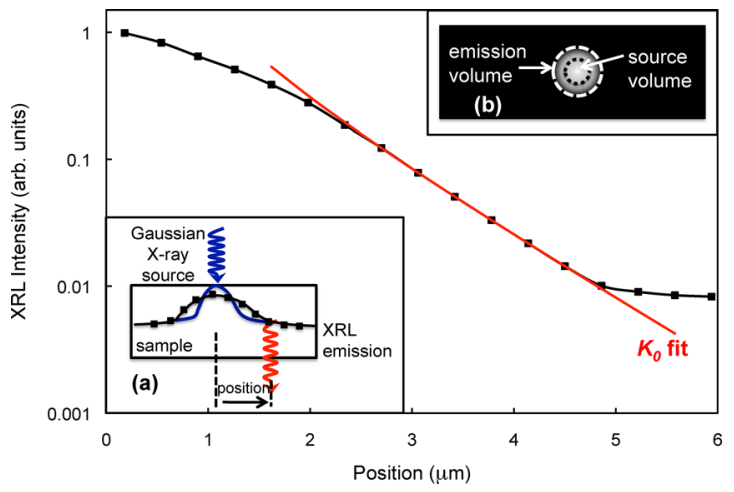

FIG. 11. (Color online) XRL emission profile from excitation in one of the crystals of the Ce:YAG bicrystal sample. The black squares plot the intensities at each pixel averaged over images of emission from excitations at a number of different spots. Inset (a) shows a schematic of the technique used to measure profiles. Inset (b) illustrates the contribution of the source volume to the total emission volume. 

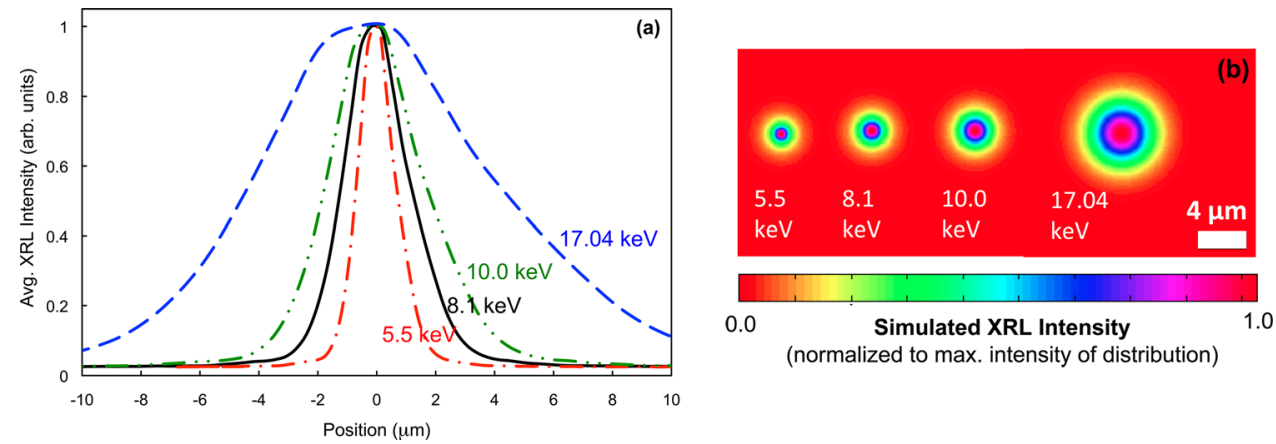

FIG. 12. (Color online) XRL emission spots from excitations with different energies in one of the crystals making up the Ce:YAG bicrystal. The crosssections of spots shown in (a) were calculated by averaging XRLM images taken at a number of different locations within the crystal. The intensity maps in (b) were simulated in two-dimensional space with no boundary condition. The hue-saturation-value of the maps (see online for color version) is normalized with respect to the maximum intensity of each individual distribution.

intensity with time represents the probability that charge carriers radiatively recombine at a given time after their generation. The decay time expresses the exponential fall-off rate of this probability. Trapping and non-radiative recombination effect the probability of radiative recombination within a given time window and therefore effect the values of decay time.$^{74,75}$ Scintillation decay times are also affected by activator ion relaxation rates, which are over 4 orders of magnitude larger for $\mathrm{Eu}^{3+}$ than $\mathrm{Ce}^{3+} .{ }^{45,76}$ Under the high-flux, steady-state excitation conditions present here, activator ions can be continuously populated, so that the relaxation rate significantly affects the time (and equivalently the distance) over which a charge carrier must hop until it finds a free activator ion. Therefore, scintillation decay times can be used as a measure of the effective charge carrier lifetimes of interest in this study.

\section{Simulated emission distributions}

Before calculating values of $s$, by fitting solutions to the diffusion equation (Eq. (1)) with the appropriate boundary condition (Eq. (5)) to XRLM data, we first confirmed that both charge carrier generation and transport could be effectively modeled. Simulated emission distributions were found to be in good agreement with the measured values. The distributions in Fig. 12(b) are solutions to the partial differential equation (PDE) in Eq. (1) with a two-dimensional, Gaussian source term centered at point $\left(x_{0}, y_{0}\right)$, given by

$$
S(x, y)=\exp \left(-\frac{\left(x-x_{0}\right)^{2}+\left(y-y_{0}\right)^{2}}{2 \sigma^{2}}\right) .
$$

TABLE II. Scintillation decay times of samples.

\begin{tabular}{lcc}
\hline \hline Sample & Decay time & Percentage \\
\hline Ce: $\mathrm{YAG}$ bicrystal & $82 \mathrm{~ns}$ & $79 \%$ \\
& $394 \mathrm{~ns}$ & $28 \%$ \\
Ce: $\mathrm{YAG}$ ceramic & $73 \mathrm{~ns}$ & $71 \%$ \\
& $578 \mathrm{~ns}$ & $11 \%$ \\
Eu: $\mathrm{Y}_{2} \mathrm{O}_{3}$ ceramic (YO1) & $0.983 \mathrm{~ms}$ & $93 \%$ \\
Eu: $\mathrm{Y}_{2} \mathrm{O}_{3}$ ceramic $(\mathrm{YO} 2)$ & $0.978 \mathrm{~ms}$ & $95 \%$ \\
\hline \hline
\end{tabular}

The PDE was solved over a 525313 node mesh within a circular area with a diameter of $75 \mu \mathrm{m}$. The diffusion coefficient used in the PDE for all four energies was calculated from the average of the calculated diffusion lengths and the scintillation decay time for the Ce:YAG crystal from which the bicrystal was cut.

The standard deviation $(\sigma)$ of $S(x, y)$ was calculated through the convolution of a Gaussian x-ray source with the interaction volumes of a single collimated $\mathrm{x}$-ray when only considering sequential photoelectron emission (i.e., the low energy limit) from the element with the largest photoelectric interaction cross-section. The three-dimensional distributions of the energy deposited by photoelectrons in $10^{3}-\mathrm{nm}^{3}$ bins were modeled using the CASINO 2.42 software package. ${ }^{77}$ These distributions were then integrated over the sample thickness to produce a two-dimensional distribution of the energy deposited by each photoelectron. The convolution of the sum of the Gaussians from the possible photoelectron energies (from excitation with the primary $\mathrm{x}$-ray or $\mathrm{x}$-ray fluorescence from the relaxation of electrons to cores energy levels in $\mathrm{Eu}, \mathrm{Ce}, \mathrm{Y}, \mathrm{Al}$, or $\mathrm{O}$ ) was fit by a Gaussian function to determine the $\sigma$ of the excitation source, i.e., the initial distribution of charge carriers with energies below the threshold for photoelectric interactions (set to $<50 \mathrm{eV}$ here).

\section{Calculation of boundary recombination velocities}

The intensities of the simulated XRL distributions for the Ce:YAG bicrystal excited by a source centered at different positions with respect to a boundary are shown in Fig. 13. The position $\left(x_{0}, y_{0}\right)$ was varied to simulate the spotby-spot excitations measured by XRLM. Solutions were plotted for a number of different values of $s$ for the boundary condition in Eq. (5) and were compared to the XRLM data near a boundary. Solutions were calculated over a $75 \mu \mathrm{m} \times 75 \mu \mathrm{m}$ two-dimensional cell with linear boundaries, as in the configuration shown in Fig. 13(b). Recombination velocities for the grain boundaries were determined by comparing XRLM results to simulated emission spot intensities for different values of $s$. Table I shows the values of $s$ calculated through this method.

Based on these results, a number of important trends were observed. Firstly, as recombination velocity increased, 

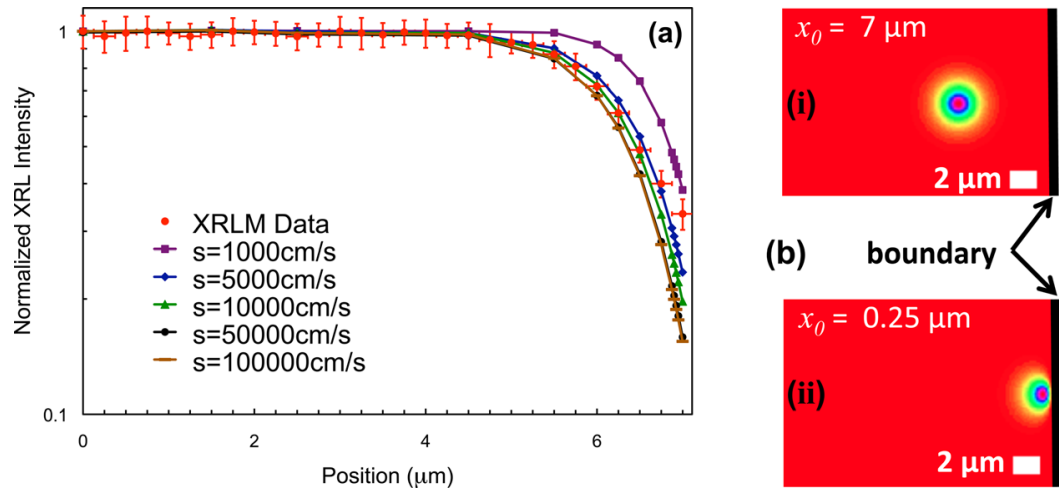

FIG. 13. (Color online) Experimental and simulated XRL intensity at different excitation spots within $7 \mu \mathrm{m}$ of a boundary. The boundary is located at the $7 \mu \mathrm{m}$ marker on the plot. Five simulated line profiles are shown in (a) with different boundary recombination velocities $(s)$ along with XRLM data. The intensity maps in (b) show the simulated distributions in two-dimensional space with the boundary condition in Eq. (5) at the righthand surface of the figures and an $s=10000 \mathrm{~cm} / \mathrm{s}$ for identical Gaussian excitations centered at (i) $7 \mu \mathrm{m}$ and (ii) $0.25 \mu \mathrm{m}$ from the boundary. The color map (see online for color version) scales with intensity shown in Fig. 12(b).

changes in the width and depth of the depletion region became less pronounced for a given effective diffusion coefficient. Therefore, there is little effect on the total XRL intensity from defects (e.g., traps and non-radiative recombination sites) beyond a certain concentration or rate of trapping on such sites in the immediate vicinity of a boundary. This may in part explain the minimal differences observed in the depletion regions measured across different boundaries in the same ceramic, even though the crystalline orientation of grains was random. Secondly, both the recombination velocity at the boundary and the flux rate at which charge carriers can diffuse to the boundary affected the characteristics of the depletion region. Such a mechanism preserves local thermodynamic equilibrium and is dependent on transport properties both at the boundary and within the bulk of the grains. Therefore,

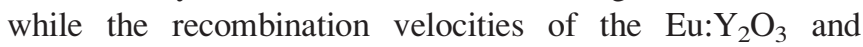
Ce:YAG ceramics characterized in this study were similar, their depletion widths and depths were quite different. Lastly, even though the $D / s$-ratio for $E u: \mathrm{Y}_{2} \mathrm{O}_{3}$ was nearly four orders of magnitude smaller than that of $\mathrm{Ce} Y \mathrm{YAG}$, its much smaller $D$ led to a smaller charge carrier flux rate in response to the same concentration gradient, which caused a smaller depletion region. In this way, the transport properties within the bulk of the grains had a significant affect on the depletion of charge carriers near the boundary.

It should be noted that the error in the calculation for values of $s$ was quite large $(>2250 \mathrm{~cm} / \mathrm{s}$ and $<40500 \mathrm{~cm} / \mathrm{s})$ because of the spread in the measured XRL intensities and the small differences in simulated intensity for different values of $s$. Calculated mean values were, however, found to be similar to surface and boundary recombination velocities reported in the literature. ${ }^{78-82}$ Most importantly, the trends observed here are still accurate, even with the large error, and because the value of $s$ appears to be less significant than $D$, there was much less error in the calculated values of bulk XRL intensity presented in Sec. IV E.

\section{E. Effect of grain boundaries on bulk XRL intensity}

Figure 14 shows the simulated effect of grain size on XRL intensity compared to the case of an infinite single crys- tal of Eu: $\mathrm{Y}_{2} \mathrm{O}_{3}$ using the effective diffusion lengths and recombination velocities given in Table I. These values were compared to the measured values for bulk XRL intensity for a set of optically transparent Eu: $\mathrm{Y}_{2} \mathrm{O}_{3}$ ceramics processed
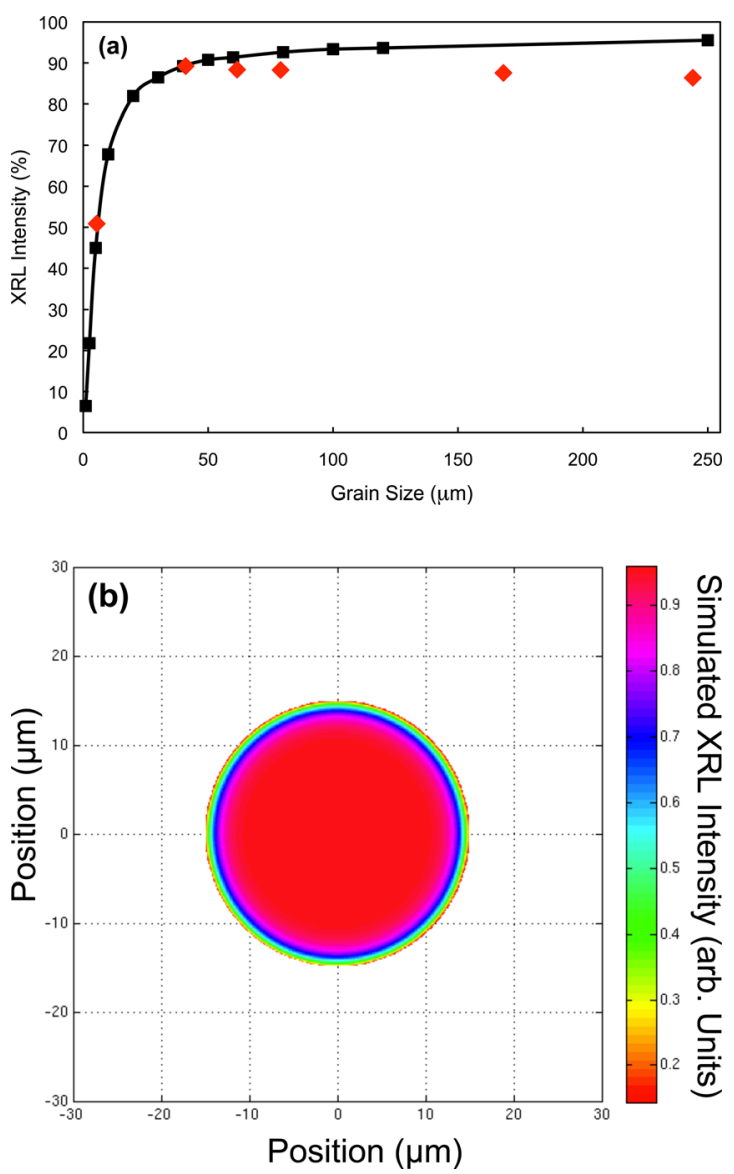

FIG. 14. (Color online) (a) Simulated (squares) and experimental (diamonds) bulk XRL intensities as a function of ceramic grain size relative to the infinite single crystal case for Eu: $\mathrm{Y}_{2} \mathrm{O}_{3}$. Numerical solutions to Eq. (1) with a homogeneous source term over the entire grain and with boundary condition in Eq. (5) at circular boundaries with different radii were integrated over the entire solution space to calculate the XRL intensity. A recombination velocity of $s=4500 \mathrm{~cm} / \mathrm{s}$ (the measured value for YO2) was used. (b) Example of an intensity map of simulated distribution in twodimensional space under bulk excitation of a ceramic grain. 
under similar conditions to the YO2 sample. Ceramics were hot-pressed at different temperatures to produce different grain sizes. Otherwise, they were processed under identical conditions. In order to minimize the effect of oxygen nonstoichiometry on their bulk XRL intensity, we compared ceramics that were air annealed for $72 \mathrm{~h}$ to our simulated values. $^{83}$

The prediction was found to be in good agreement with ceramics of Eu: $\mathrm{Y}_{2} \mathrm{O}_{3}$ with this grain size range. As an example, when comparing a Eu: $\mathrm{Y}_{2} \mathrm{O}_{3}$ ceramic with a grain size of $5.5 \mu \mathrm{m}$ to one with a grain size of $34.1 \mu \mathrm{m}$, our model predicted a relative XRL intensity of $58 \%$, and a relative bulk XRL intensity of $63 \%$ was measured for samples with these same grain sizes.

\section{CONCLUSIONS}

We have shown that $\mathrm{x}$-ray radioluminescence microscopy (XRLM) may be used to directly visualize the scintillation emission near grain boundaries in transparent ceramics. When coupled with chemical and structural analysis on grain boundaries, which in certain cases may be taken simultaneous to XRLM imaging, XRLM was found to be a powerful technique that can be used to study the origin of grain boundary effects on bulk luminosity and scintillation. We have also shown that emission profiles measured through this method can be used to calculate charge carrier transport properties in both optoelectronic semiconductors (e.g., $\mathrm{GaAs}$ ) and inorganic, insulating scintillator materials (e.g., $\left.\mathrm{Eu}: \mathrm{Y}_{2} \mathrm{O}_{3}, \mathrm{Ce}: \mathrm{YAG}\right)$. Effective diffusion lengths were calculated from emission distributions by fitting their exponentiallike tails with Bessel functions in order to isolate the contributions to the distributions from charge carrier generation and transport from each other. Measured transport parameters, along with the boundary recombination velocity, were also used to model observed localized emission intensity near grain boundaries. Values of recombination velocities were able to accurately predict the effect of grain size on bulk scintillator luminosity.

Symmetric regions of emission intensity depletion were measured in both Eu: $\mathrm{Y}_{2} \mathrm{O}_{3}$ and Ce:YAG ceramic and bicrystal samples. The width of the depletion region around the grain boundaries were $\sim 1 \mu \mathrm{m}$ for Eu: $\mathrm{Y}_{2} \mathrm{O}_{3}$ and $\sim 2 \mu \mathrm{m}$ for Ce:YAG. In the case of Eu: $\mathrm{Y}_{2} \mathrm{O}_{3}$, the depletion region originated from charge carrier trapping or non-radiative recombination. This trapping and non-radiative recombination appeared to have occurred primarily within a more limited region right at the grain boundary, which nonetheless depletes the charge carrier concentration over larger volume. In $\mathrm{Eu}: \mathrm{Y}_{2} \mathrm{O}_{3}$, a significant decrease in emission intensity was predicted below a grain size of $\sim 20 \mu \mathrm{m}$. These results were consistent with preliminary results on $\mathrm{Eu}: \mathrm{Y}_{2} \mathrm{O}_{3}$ ceramics with $<5 \mu \mathrm{m}$ grain sizes and literature values.

The XRLM method can readily be extended to other luminescent materials, particularly insulators, to characterize the effect of grain boundaries and other structural defects on emission under high-flux x-ray irradiation. Simultaneously coupling XRLM with acquisition from other x-ray analytical techniques, such as $\mathrm{x}$-ray absorption spectroscopy, $\mathrm{x}$-ray micro-diffraction, and pulsed x-ray excitation, would make XRLM an even more versatile tool.

\section{ACKNOWLEDGMENTS}

This research was supported by the Defense Threat Reduction Agency under grant no. HDTRA1-06-CWMDBR. XRLM measurements were carried out at the Stanford Synchrotron Radiation Lightsource, a national user facility operated by Stanford University on behalf of the U.S. Department of Energy, Office of Basic Energy Sciences. The authors would like to thank Sam Webb at SSRL, Piero Pianetta at SLAC, and Nancy Haegel at the Naval Postgraduate School for helpful discussions; Martin Nikl at Institute of Physics, Academy of Science of the Czech Republic and Edith Bourret-Courchesne and Stephen Hanrahan at Lawrence Berkeley National Laboratory for assistance with characterizing $\mathrm{x}$-ray radioluminescence and scintillation decay of bulk ceramic samples; and Ed Barnard, Ann Marshall, and Chuck Hitzman at Stanford University for assistance with confocal microscopy, TEM, and SIMS.

\footnotetext{
${ }^{1}$ R. Nakamura, J. Am. Ceram. Soc. 82(9), 2407 (1999).

${ }^{2}$ C. Greskovich and S. Duclos, Annu. Rev. Mater. Sci. 27, 69 (1997).

${ }^{3}$ E. V. van Loef, W. M. Higgins, J. Glodo, C. Brecher, A. Lempicki, V. Venkataramani, W. W. Moses, S. E. Derenzo, and K. S. Shah, IEEE Trans. Nucl. Sci. 54(3), 741 (2007).

${ }^{4}$ T. Yanagida, H. Takahashi, T. Ito, D. Kasama, T. Enoto, M. Sato, S. Hirakuri, M. Kokubun, K. Makishima, T. Yanagitani, H. Yagi, T. Shigeta, and T. Ito, IEEE Trans. Nucl. Sci. 52(5), 1836 (2005).

${ }^{5}$ D. J. Wisniewski, L. A. Boatner, J. S. Neal, G. E. Jellison, J. O. Ramey, A. North, M. Wisniewska, A. E. Payzant, J. Y. Howe, A. Lempicki, C. Brecher, and J. Glodo, IEEE Trans. Nucl. Sci. 55(3), 1501 (2008).

${ }^{6}$ P. Yang, T. J. Boyle, N. S. Bell, M. R. Sanchez, L. A. M. Ottley, and C. F. Chen, "Fabrication of Large-Volume, Low-Cost Ceramic Lanthanum Halide Scintillators for Gamma Ray Detection," Sandia National Laboratories Report SAND2008-6978, October 2008.

${ }^{7}$ S. R. Podowitz, R. M. Gaumé, W. T. Hong, A. Laouar, and R. S. Feigelson, IEEE Trans. Nucl. Sci. 57(6), 3827 (2010).

${ }^{8}$ O. B. Drury, N. J. Cherepy, T. A. Hurst, and S. A. Payne, IEEE Nuclear Science Symposium Conference Record, Orlando, FL, 24 October-1 November 2009, pp. 1585-1587.

${ }^{9}$ N. J. Cherepy, J. D. Kuntz, Z. M. Seeley, S. E. Fisher, O. B. Drury, B. W. Sturm, T. A. Hurst, J. J. Roberts, and S. A. Payne, Proc. SPIE 7805, 78050I (2010).

${ }^{10} \mathrm{~N}$. Chandra and D. A. Langan, "Gemstone detector: Dual energy imaging via fast kVp switching," in Dual Energy CT in Clinical Practice, edited by T. Johnson, C. Fink, S. O. Schönberg, and M. F. Reiser (Springer, New York, 2011), pp. 35-41.

${ }^{11}$ Y. Yanagawa, N. Tomiyama, O. Honda, A. Kikuyama, H. Sumikawa, A. Inoue, K. Tobino, M. Koyama, and M. Kudo, Radiology 255(3), 944 (2010).

${ }^{12}$ D. J. Wisniewski, L. A. Boatner, J. S. Neal, G. E. Jellison, J. O. Ramey, M. Wisniewska, A. North, A. Lempicki, C. Brecher, and J. Glodo, Proc. SPIE 6706, 670619 (2007).

${ }^{13}$ E. Mihóková, M. Nikl, J. A. Mareš, A. Beitlerová, A. Vedda, K. Nejezchleb, K. Blažek, and C. D’Ambrosio, J. Lumin. 126, 77 (2007).

${ }^{14}$ R. H. Bartram, A. Lempicki, L. A. Kappers, and D. S. Hamilton, J. Lumin. 106, 169 (2004)

${ }^{15}$ E. Zych, C. Brecher, A. J. Wojtowicz, and H. Lingertat, J. Lumin. 75, 193 (1997).

${ }^{16}$ N. J. Cherepy, J. D. Kuntz, T. M. Tillotson, D. T. Speaks, S. A. Payne, B. H. T. Chai, Y. Porter-Chapman, and S. E. Derenzo, Nucl. Instrum. Methods Phys. Res. A 579, 38 (2007).

${ }^{17}$ M. Nikl, Meas. Sci. Technol. 17, R37 (2006).

${ }^{18}$ M. Nikl, J. A. Mares, N. Solovieva, H.-L. Li, X.-J. Liu, L. P. Huang, I. Fontana, M. Fasoli, A. Vedda, and C. D’Ambrosio, J. Appl. Phys. 101(3), 033515 (2007).

${ }^{19}$ F. Greuter and G. Blatter, Semicond. Sci. Technol. 5, 111 (1990).
} 
${ }^{20}$ H. F. Mataré, J. Appl. Phys. 59(1), 97 (1986).

${ }^{21}$ Y. Sato, T. Yamamoto, and Y. Ikuhara, J. Am. Ceram. Soc. 90(2), 337 (2007).

${ }^{22}$ A. V. Virkar, J. Chen, C. W. Tanner, and J.-W. Kim, Solid State Ionics 131(1-2), 189 (2000).

${ }^{23}$ Y. Yan, R. Noufi, and M. M. Al-Jassim, Phys. Rev. Lett. 96, 205501 (2006).

${ }^{24}$ J. Palm, J. Appl. Phys. 74(2), 1169 (1993).

${ }^{25}$ S. J. Rosner, E. C. Carr, M. J. Ludowise, G. Girolami, and H. I. Erikson, Appl. Phys. Lett. 70(4), 420 (1997).

${ }^{26}$ A. Gustafsson, M.-E. Pistol, L. Montelius, and L. Samuelson, J. Appl. Phys. 84(4), 1715 (1998).

${ }^{27}$ A. J. Wojtowicz, J. Glodo, A. Lempicki, and C. Brecher, J. Phys.: Condens. Matter 10, 8401 (1998).

${ }^{28}$ A. Lempicki and R. H. Bartram, J. Lumin. 81, 13 (1999).

${ }^{29}$ G. Bizarri, W. W. Moses, J. Singh, A. N. Vasil'ev, and R. T. Williams, J. Appl. Phys. 105, 044507 (2009).

${ }^{30}$ R. T. Williams, J. Q. Grim, Q. Li, K. B. Ucer, and W. W. Moses, Phys. Status Solidi B 248(2), 426 (2011).

${ }^{31}$ C. Donolato and P. Venturi, Phys. Status Solidi A 73, 377 (1982).

${ }^{32}$ A. Jakubowicz, J. Appl. Phys. 59(6), 2205 (1986).

${ }^{33}$ W. Hergert, P. Reck, L. Pasemann, and J. Schreiber, Phys. Status Solidi A 101, 611 (1987).

${ }^{34}$ N. M. Haegel, J. D. Fabbri, and M. P. Coleman, Appl. Phys. Lett. 84(8), 1329 (2004).

${ }^{35}$ S. Webb, "Applications of Microscale XAS and XAS Imaging," in Structural Molecular Biology Low-Z XAS Summer School (SLAC National Accelerator Laboratory, Menlo Park, CA, 2010).

${ }^{36}$ N. M. Haegel, T. J. Mills, M. Talmadge, C. Scandrett, C. L. Frenzen, H. Yoon, C. M. Fetzer, and R. R. King, J. Appl. Phys. 105, 023711 (2009).

${ }^{37}$ A. P. Patel, M. R. Levy, R. W. Grimes, R. M. Gaume, R. S. Feigelson, K. J. McClellan, and C. R. Stanek, Appl. Phys. Lett. 93, 191902 (2008).

${ }^{38}$ Y. Dong, G. Zhou, J. Xu, G. Zhao, F. Su, L. Su, G. Zhang, D. Zhang, H. Li, and J. Si, Mater. Res. Bull. 41, 1959 (2006).

${ }^{39}$ Y. Zorenko, A. Voloshinovskii, I. Konstankevych, V. Kolobanov, V. Mikhailin, and D. Spassky, Radiat. Meas. 38, 677 (2004).

${ }^{40}$ F. A. Selim, D. Solodovnikov, M. H. Weber, and K. G. Lynn, Appl. Phys. Lett. 91, 104105 (2007).

${ }^{41}$ T. Y. Fan and J. L. Daneu, Appl. Opt. 37(9), 1635 (1998).

${ }^{42}$ S. R. Podowitz, R. Gaumé, and R. S. Feigelson, J. Am. Ceram. Soc. 93(1), $82(2010)$.

${ }^{43}$ Z. Fu, S. Zhou, T. Pan, and S. Zhang, J. Lumin. 124(2), 213 (2007).

${ }^{44}$ Y. Nigara, Jpn. J. Appl. Phys. 7(4), 404 (1968).

${ }^{45}$ N. Rakov, W. Lozano, G. S. Maciel, and C. B. de Araújo, Chem. Phys. Lett. 428, 134 (2006).

${ }^{46}$ C. D. Greskovich, D. A. Cusano, and F. A. DiBianca, U.S. Patent 4,518, 546 (May 21, 1985)

${ }^{47}$ M. I. Peters and I. E. Reimanis, J. Am. Ceram. Soc. 86(5), 870 (2003).

${ }^{48}$ V. V. Nagarkar, J. S. Gordon, T. K. Gupta, S. Vasile, P. Gothoskar, M. R. Squillante, and G. Entine, IEEE Trans. Nucl. Sci. 44(3), 885 (1997).

${ }^{49}$ B. L. Abrams and P. H. Holloway, Chem. Rev. 104(12), 5783 (2002).

${ }^{50}$ M. O. Ramirez, J. Wisdom, H. Li, Y. L. Aung, J. Stitt, G. L. Messing, V. Dierolf, Z. Liu, A. Ikesue, R. L. Byer, and V. Gopalan, Opt. Express 16(9), 5965 (2008).

${ }^{51}$ I. Dawson, P. D. Bristowe, M.-H. Lee, M. C. Payne, M. D. Segall, and J. A. White, Phys. Rev. B 54(19), 13727 (1996).
${ }^{52}$ S.-D. Mo, W. Y. Ching, and R. H. French, J. Am. Ceram. Soc. 79(3), 627 (1996).

${ }^{53}$ S.-D. Mo, W. Y. Ching, M. F. Chisholm, and G. Duscher, Phys. Rev. B 60(4), 2416 (1999).

${ }^{54}$ M. Kohyama, R. Yamamoto, Y. Ebata, and M. Kinoshita, J. Phys. C 21, 3205 (1988)

${ }^{55}$ T. Kizuka, M. Iijima, and N. Tanaka, Philos. Mag. A 77(2), 413 (1998).

${ }^{56}$ K. P. McKenna and A. L. Shluger, Nature Mater. 7, 859 (2008).

${ }^{57}$ B. L. Henke, E. M. Gullikson, and J. C. Davis, At. Data Nucl. Data Tables 54(2), 181 (1993).

${ }^{58}$ N. E. Munoz, S. R. Gilliss, and C. B. Carter, Surf. Sci. 573, 391 (2004).

${ }^{59}$ Y. Yan, M. F. Chisholm, G. Duscher, A. Maiti, S. J. Pennycook, and S. T. Pantelides, Phys. Rev. Lett. 81(17), 3675 (1998).

${ }^{60}$ D. Vanmaekelbergh and P. E. de Jongh, Phys. Rev. B 61(7), 7699 (2000).

${ }^{61}$ J. A. Anta, J. Nelson, and N. Quirke, Phys. Rev. B 65, 125324 (2002).

${ }^{62}$ L. Ottolini, F. Cámara, F. C. Hawthorne, and J. Stirling, Am. Mineral. 87, 1477 (2002)

${ }^{63}$ W. Shockley, G. L. Pearson, and J. R. Haynes, Bell Syst. Tech. J. 28, 344 (1949).

${ }^{64}$ V. Liuolia, S. Marcinkevičius, Y.-D. Lin, H. Ohta, S. P. DenBaars, and S. Nakamura, J. Appl. Phys. 108, 023101 (2010).

${ }^{65}$ Á. R. Vasconcellos, M. J. S. P. Brasil, R. Luzzi, A. A. P. Silva, and A. H. S. Leite, J. Appl. Phys. 106, 043503 (2009).

${ }^{66}$ X. Liu and D. E. Aspnes, Appl. Phys. Lett. 93, 203104 (2008).

${ }^{67}$ S. Yu. Karpov and Yu. N. Makarov, Appl. Phys. Lett. 81(25), 4721 (2002).

${ }^{68}$ F. Cao, G. Oskam, G. J. Meyer, and P. C. Searson, J. Phys. Chem. 100, 17021 (1996).

${ }^{69}$ P.-T. Hsiao, Y.-L. Tung, and H. Teng, J. Phys. Chem. C 114, 6762 (2010).

${ }^{70}$ J. Bisquert, J. Phys. Chem. B 108, 2323 (2004).

${ }^{71}$ F. W. Schmidlin, Philos. Mag. B 41(5), 535 (1980).

${ }^{72}$ D. R. Luber, F. M. Bradley, N. M. Haegel, M. C. Talmadge, M. P. Coleman, and T. D. Boone, Appl. Phys. Lett. 88, 163509 (2006).

${ }^{73}$ M. Lax, J. Appl. Phys. 49(5), 2796 (1978).

${ }^{74}$ M. Nikl, Phys. Status Solidi A 202(2), 201 (2005).

${ }^{75}$ S. E. Derenzo, M. J. Weber, and M. K. Klintenberg, Nucl. Instrum. Methods Phys. Res. A 486, 214 (2002).

${ }^{76}$ M. Moszyński, T. Ludziejewski, D. Wolski, W. Klamra, and L. O. Norlin, Nucl. Instrum. Methods Phys. Res. A 345, 461 (1994).

${ }^{77}$ D. Drouin, A. Réal Couture, D. Joly, X. Tastet, V. Aimez, and R. Gauvin, Scanning 29, 92 (2007).

${ }^{78}$ D. E. Burk, S. Kanner, J. E. Muyshondt, D. S. Shaulis, and P. E. Russell, J. Appl. Phys. 54(1), 169 (1983).

${ }^{79}$ S. A. Bukesov and D. Y. Jeon, Appl. Phys. Lett. 81(12), 2184 (2002).

${ }^{80}$ Y. Rosenwaks, L. Burstein, Y. Shapira, and D. Huppert, Appl. Phys. Lett. 57(5), 458 (1990).

${ }^{81}$ M. Passlack, M. Hong, E. F. Schubert, J. R. Kwo, J. P. Mannaerts, S. N. G. Chu, N. Moriya, and F. A. Thiel, Appl. Phys. Lett. 66(5), 625 (1995).

${ }^{82}$ L. W. Tu, W. C. Kuo, K. H. Lee, P. H. Tsao, C. M. Lai, A. K. Chu, and J. K. Sheu, Appl. Phys. Lett. 77(23), 3788 (2000).

${ }^{83}$ S. R. Podowitz, S. Hanrahan, E. Bourett-Courchesne, N. Cherepy, R. M. Gaume, and R. S. Feigelson, "Effect of Grain Size and Processing on Light Yield of Eu: $\mathrm{Y}_{2} \mathrm{O}_{3}$ Transparent Ceramics," in Symposium on Radiation Measurements and Applications (SORMA XII) (University of Michigan, Ann Arbor, MI, 2010). 